Arq. Bras. Med. Vet. Zootec., v.66, n.2, p.355-359, 2014

\title{
Condrossarcoma mesenquimal extraesquelético em um gato: relato de caso
}

\author{
[Extraskeletal mesenchymal chondrosarcoma in a cat: case report] \\ T.N. Guim ${ }^{1}$, C.B. Cartana $^{2}$, C.G. Fernandes ${ }^{1}$, T.N. Guim ${ }^{3}$, L.F.J. Gaspar ${ }^{1}$ \\ ${ }^{1}$ Faculdade de Veterinária - Universidade Federal de Pelotas - UFPel - Pelotas, RS \\ ${ }^{2}$ Faculdade de Itapiranga - FAI - Itapiranga, SC \\ ${ }^{3}$ Faculdade de Medicina Veterinária - Unipampa - Uruguaiana-RS
}

\begin{abstract}
RESUMO
Condrossarcoma mesenquimal extraesquelético (CME) é um neoplasma maligno e raro em animais domésticos. Descreve-se um caso de CME em uma gata que apresentava uma massa firme, brancoamarelada, medindo $18 \mathrm{~cm}$ de diâmetro, aderida à musculatura do membro pélvico esquerdo. $\mathrm{O}$ exame citológico revelou presença de células fusiformes individualizadas pleomórficas e agregados de pequenas células ovais, sem bordas definidas em meio à matriz intercelular amorfa. Devido à impossibilidade de tratamento e ao prognóstico desfavorável, foi realizada eutanásia. Microscopicamente foram observadas células fusiformes indiferenciadas e agregados de células condroides pleomórficas. O diagnóstico de CME foi confirmado pelas técnicas de azul alciano, tricrômico de Masson e pela prova imunoistoquímica, utilizando-se anticorpos antivimentina.
\end{abstract}

Palavras-chave: gato, neoplasia, condrossarcoma extraesquelético

\begin{abstract}
Extraskeletal mesenchymal chondrosarcoma (EMC) is a rare malignant tumor in domestic animals. We described a case of EMC in a cat with a mass measuring $18 \mathrm{~cm}$ in diameter, yellowish-white and firm attached to the muscles in left hind limb. Cytological examination revealed the presence of individual pleomorphic spindle cells and clusters of small oval cells with no hard edges in the midst of an amorphous intercellular matrix. Due to the impossibility of treatment and poor prognosis, the cat was euthanized. Microscopically undifferentiated spindle cells and clusters of pleomorphic chondroid cells were observed. The CME diagnosis was confirmed with thealcian blue, Masson's trichrome and immunohistochemistry techniques, using antivimentin antibodies.
\end{abstract}

Keywords: cat, neoplasm, extraskeletal chondrosarcoma

\section{INTRODUÇÃO}

O condrossarcoma é um neoplasma mesenquimal maligno que se origina das células cartilaginosas e contém quantidades variáveis de matriz condroide e fibrilar e não possui matriz osteoide. É o segundo tumor ósseo primário mais frequente em cães e humanos (Dernell et al., 2007). Esse tipo de neoplasma se desenvolve tanto no sistema esquelético como em outros sítios (Thompson e Pool, 2002). Os condrossarcomas são classificados histologicamente em mixoides, mais frequentemente observados em sítios esqueléticos, e mesenquimais, mais comuns em sítios extraesqueléticos (Casadei et al., 1991).

O condrossarcoma mesenquimal extraesquelético (CME) é raro em animais domésticos e foi descrito em cães (Munday e Prahl, 2002), felinos (Romanucci et al., 2005), bovinos (Uno et al., 1989) e equinos (Wilson e Anthony, 2007). A etiologia desses tumores é desconhecida (Nesi et al., 2000), porém é possível que ocorra como uma forma de sarcoma pós-vacinal em felinos (Hendrick e Brooks, 1994).

Recebido em 3 de julho de 2012

Aceito em 5 de novembro de 2013

E-mail: thomasguim@hotmail.com 


\section{DESCRIÇÃO DO CASO}

Foi atendida no Hospital Veterinário da Universidade Federal de Pelotas (HV-UFPel) uma gata de raça indefinida, com 12 anos de idade e histórico de claudicação e aumento de volume no membro pélvico esquerdo. Ao exame físico, evidenciou-se uma massa subcutânea firme, com cerca de $15 \mathrm{~cm}$ de diâmetro, aderida na face lateral da coxa esquerda, projetando-se para a região lombossacra (Fig. 1A). O animal apresentava dor à palpação. $\mathrm{O}$ exame neurológico indicou perda proprioceptiva e da função motora do membro afetado. Foram preconizados exames radiológico, hematológico, bioquímicos e citológico, no entanto o proprietário não autorizou sua realização. Foi sugerida a remoção cirúrgica da massa, mas o proprietário optou por não tratar o animal. Dessa forma, prescreveu-se terapia analgésica como medida paliativa.

Quatro semanas após a primeira consulta, o animal foi encaminhado novamente ao $\mathrm{HV}$ UFPel por apresentar aumento evidente da massa neoplásica, além de anorexia, caquexia e estupor. Foi realizado exame citológico por meio de aspiração com agulha fina. Neste, verificaram-se baixa celularidade, presença de células fusiformes individualizadas e agregados de pequenas células ovais, sem bordas definidas, em meio à matriz intercelular amorfa. Foi, então, estabelecido o diagnóstico prévio de sarcoma. Devido à idade avançada da gata, à condição clínica, à impossibilidade de remoção cirúrgica do tumor e ao prognóstico desfavorável, realizou-se a eutanásia.

$\mathrm{Na}$ necropsia, observou-se massa subcutânea aderida à musculatura do membro posterior esquerdo, do flanco e da região paravertebral. $\mathrm{O}$ tumor era multinodular, branco-amarelado, firme e media $18 \mathrm{~cm}$ de diâmetro (Fig. 1B). Ao corte, era homogêneo e apresentava área central de necrose. Não foram observadas metástases. Fragmentos do neoplasma foram fixados em formalina a $10 \%$, processados como de rotina e corados para hematoxilina-eosina (HE), azul alciano (AA) e tricrômico de Masson (TM). Adicionalmente, análise imunoistoquímica foi realizada com anticorpo primário antivimentina (1:100, clone V9, DAKO), utilizando-se a técnica da estreptavidina-biotina-peroxidase.

Histologicamente, nos cortes corados pelo HE, foram observados dois padrões distintos de células neoplásicas. Evidenciaram-se proliferação de células fusiformes indiferenciadas, com citoplasma eosinofílico e pouco delimitado, núcleos vesiculosos, pleomórficos ovoides a alongados, nucléolos evidentes e duas a três mitoses por campo (Fig. 1C, objetiva de 400x). Adicionalmente, entremeadas a essas células, foram observadas áreas contendo agregados de células condroides pleomórficas imersas em matriz fibrilar eosinofílica, representadas por lacunas preenchidas por núcleos levemente basofílicos, frequentemente múltiplos e bizarros (Fig. 1D). A avaliação imunoistoquímica revelou positividade difusa da vimentina no citoplasma de células condroides e fusiformes indiferenciadas (Fig. $1 \mathrm{E}$ e F). Na coloração de AA, a matriz corou-se fracamente de azul claro (Fig. 1H), e na coloração de TM, as fibras colágenas coraram-se de verde intenso (Fig. $1 G)$.

\section{DISCUSSÃO}

Condrossarcoma extraesquelético (CE) é um neoplasma caracterizado pela proliferação de células malignas com diferenciação condroide, sem associação com o sistema esquelético (Thompson e Pool, 2002). Em cães, o CE tem sido relatado em alguns órgãos e tecidos (Munday e Prahl, 2002), porém em felinos as informações são escassas. Há artigos que relatam a ocorrência desse tumor no tecido subcutâneo da região lombossacra (Romanucci et al., 2005), nas regiões escapular e digital (Brown et al., 1978). Hendrick e Brooks (1994) relataram um caso de condrossarcoma como uma forma de sarcoma pós-vacinal felino. No presente caso, observou-se que a massa apresentava localização subcutânea e na necropsia constatou-se ausência de relação entre o neoplasma e o sistema osseoarticular. 


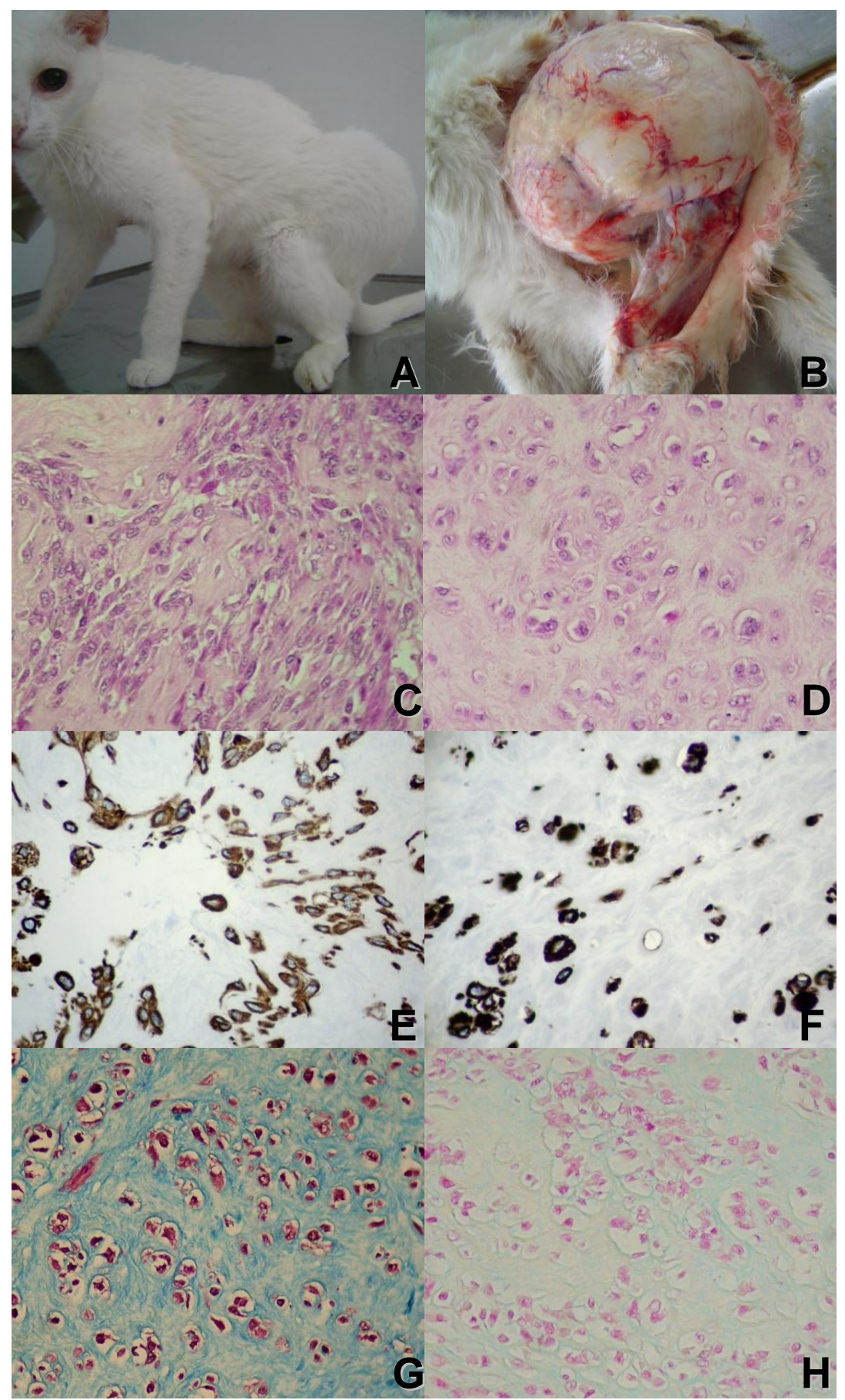

Figura 1. Condrossarcoma mesenquimal extraesquelético em felino. A - Massa subcutânea arredondada e volumosa na face lateral da coxa esquerda do felino. B - Neoplasma bem delimitado de coloração brancoamarelada, aderido à musculatura. C - Proliferação de células fusiformes indiferenciadas (HE, Obj. 40x). D - Agregados de células condroides pleomórficas, imersas em matriz fibrilar eosinofílica (HE, Obj. 40x). E - Células fusiformes apresentando positividade imunoistoquímica para vimentina (Obj. 40x). F Células condroides apresentando positividade imunoistoquímica para vimentina (Obj. 40x). G - Matriz colágena corada de verde pela coloração de TM (Obj. 40x). H - Matriz condroide corada fracamente de azul, evidenciando a escassez de glicoproteína típica dessa estrutura (AA, Obj. 40x). 
Condrossarcoma tem sido descrito como um possível tipo de sarcoma pós-vacinal felino (Hendrick e Brooks, 1994). No entanto, vacinações ou outros tipos de inoculação e traumas no sítio tumoral não foram relatados pelo proprietário. Além disso, no exame histopatológico, não foram observadas lesões típicas daquelas encontradas em sarcomas associados à vacinação, como infiltrado linfocítico peritumoral e presença de células histiocíticas fagocitando material amorfo (Hendrick e Brooks, 1994).

A citologia foi útil para determinar que se tratava de uma lesão neoplásica maligna de origem mesenquimal. $\mathrm{O}$ diagnóstico citológico de $\mathrm{CME}$, no entanto, não foi conclusivo, devido à diversidade de características histomorfológicas dos componentes desse neoplasma. Outros autores também relataram dificuldade para diagnosticar CME em preparados citológicos (Munday e Prahl, 2002).

Histologicamente, dois diferentes subtipos de condrossarcomas são reconhecidos: mixoide e mesenquimal (Casadei et al., 1991). No presente caso, o neoplasma foi classificado como subtipo mesenquimal, devido à diversidade de arranjos das células mesenquimais primitivas, ao padrão da matriz extracelular e à imunopositividade para vimentina. Observou-se matriz condroide evidente, a qual era eosinofílica nos cortes corados em HE. Por meio das colorações de TM e AA, constatou-se que a matriz era composta predominantemente de colágeno e, em menor proporção, de material glicoproteico. Essas características são idênticas às observadas na matriz da cartilagem fibrosa (Junqueira e Carneiro, 2004). Portanto, o diagnóstico de CME foi firmado com base nas características histomorfológicas, tintoriais e imunoistoquímicas do neoplasma.

Existem poucas informações em relação ao comportamento biológico de CME em animais domésticos. Em humanos é descrita alta taxa de recorrência e o desenvolvimento de metástases (Casadei et al., 1991). Por outro lado, na espécie canina, as lesões metastáticas são raramente observadas (Munday e Prahl, 2002). Neste caso, a despeito do tamanho da massa neoplásica e do tempo de evolução, não foram observadas lesões metastáticas, embora houvesse invasão local e características histomorfológicas corroborando o alto potencial de malignidade.

A excisão cirúrgica é a terapia de escolha para CME (Scott et al., 1996). No entanto, nesse caso, não foi possível a adoção dessa modalidade de tratamento. Há descrição de um caso de CME de localização subcutânea em um felino no qual a excisão cirúrgica foi realizada, sem histórico de recorrência e metástase seis meses após o procedimento (Romanucci et al., 2005).

\section{CONCLUSÕES}

Em cães e, principalmente, em gatos, as informações referentes ao tratamento, comportamento biológico e prognóstico do $\mathrm{CME}$ são escassas. Da mesma forma que são pouco comuns as informações acerca da etiologia. Em razão da arquitetura histomorfológica complexa do CME, o diagnóstico citológico é difícil. A avaliação histológica, aliada às provas histoquímicas e imunoistoquímicas, foi essencial para a realização do diagnóstico. Este relato consta como o primeiro caso de $\mathrm{CME}$ em felino descrito no Brasil

\section{REFERÊNCIAS}

BROWN, N.O.; PATNAIK, A.K.; MOONEY, S. et al. Soft tissue sarcomas in the cat. J. Am. Vet. Med. Assoc., v.173, p.744-749, 1978.

CASADEI, R.; RICCI, M.; RUGGIERI, P. et al. Chondrosarcoma of the soft tissues. Two different sub-groups. J. Bone and Joint Surgery British, v.73, p.162-168, 1991.

DERNELL, W.S.; EHRHART, N.P.; STRAW, R.C. $e t$ al. Tumors of skeletetal system. In: WITHROW, S.J.; VAIL, D.M. Small Animal Clinical Oncology, 4.ed., Canada: Saunders Elsevier, 2007. p.568.

HENDRICK, M.J.; BROOKS, J.J. Post vaccinal sarcomas in the cat: histology and imunohistochemistry. Vet. Pathol., v.31, p.126-129, 1994.

JUNQUEIRA, L.C.; CARNEIRO, J. Tecido cartilaginoso. In: ___. Histologia básica. 10.ed. Rio de Janeiro: Guanabara Koogan, 2004. p.130-135.

MUNDAY, J.S.; PRAHL, A. Retroperitoneal extraskeletal mesenchymal chondrosarcoma in a dog. J. Vet. Diagnostic Investigation, v.14, p.498-500, 2002. 
NESI, G.; PEDEMONTE, E.; GORI, F. Extraskeletal mesenchymal chondrosarcoma involving the heart: report of a case. Italian Heart Journal, v.1, p.435-437, 2000.

ROMANUCCI, M.; BONGIOVANNI, L.; PETRIZZI, L. et al. Cutaneous extraskeletal mesenchymal chondrosarcoma in a cat. Vet. Dermatol., v.16, p.121124, 2005.

SCOTT, D.W.; MILLER, W.H.; GRIFFIN, C.E. Tumores neoplásicos e não neoplásicos. In:

Dermatologia de pequenos animais. 5.ed. Rio de Janeiro: Interlivros, 1996. p.926-1054.
THOMPSON, K.G.; POOL, R.R. Tumors of bones. In: MEUTEN, D.J. Tumors in domestic animals. 4.ed. Iowa: Iowa State Press, 2002. p.245-317.

UNO, K.; KATAOKA, H.; KADOTA, K. Extraskeletal mesenchymal chondrosarcoma in a cow. J. Comparative Pathol., v.101, p.31-38, 1989.

WILSON, G.J.; ANTHONY, N.D. Chondrosarcoma of the tongue of a horse. Austr. Vet. J., v.85, p.163165, 2007. 